\title{
Commentary: Two strands are better than one
}

\author{
Alden H. Harken, MD, ${ }^{a}$ and W. French Anderson, MD $^{\mathrm{b}}$ \\ From the ${ }^{\mathrm{a}}$ University of California, San Francisco, East Bay (retired), San Francisco, Calif; and ${ }^{\mathrm{b}}$ A Pioneer in \\ Gene Therapy. \\ Disclosures: Authors have nothing to disclose with regard to commercial support. \\ Received for publication Sept 6, 2019; revisions received Sept 6, 2019; accepted for publication Sept 6, 2019; \\ available ahead of print Oct 28, 2019. \\ Address for reprints: Alden H. Harken, MD, 1565 Alamo Way, Alamo, CA 94507 (E-mail: alden.harken68@ \\ gmail.com). \\ J Thorac Cardiovasc Surg 2020;159:1822 \\ $0022-5223 / \$ 36.00$ \\ Copyright (c) 2019 Published by Elsevier Inc. on behalf of The American Association for Thoracic Surgery \\ https://doi.org/10.1016/j.jtcvs.2019.09.078
}

One of the authors of this commentary pioneered the use of a retrovirus as a gene therapy delivery vehicle. Soon thereafter, Jim Wilson first used adenovirus, and then a couple of investigators introduced adeno-associated virus (AAV). Then came lentivirus. Many other viral vectors have been tried, but for either efficacy or safety reasons, they have not caught on. So AAV is 1 of the 4 well-characterized human gene therapy viral vectors in common use; the other 3 are adenovirus, retrovirus, and lentivirus.

Katz and colleagues ${ }^{1}$ are to be commended for publishing their important observations outside the traditional boundaries of their discipline. The ultimate goal of the medical sciences is to make patients "feel better." Surgeons are dependent on the basic sciences for direction, and basic scientists are dependent on us for relevance. Publishing in the "good journals" is undeniably persuasive to a National Institutes of Health study section, but the slam dunk ticket to funding is successful clinical application of a beautifully delineated mechanism.

To accomplish this laudable goal, clinicians must specifically define focused therapeutic hurdles, basic scientists must uncover the mechanisms of disease/therapy, and then we must learn to talk to each other. At best, surgeons practice applied immunology and molecular biology. We are the effector arm in this therapeutic spectrum.

The authors have targeted calcium cycling, which refers to the release/uptake of intracellular calcium that is dysfunctional in failing myocardium, leading to both impaired contractility/relaxation and uncontrolled cardiac excitation. The defects in calcium cycling occur at the calcium storage organelle, the sarcoplasmic reticulum. Similar defects occur in the ryanodine receptor-2 (RyR2) release channel and the sarcoplasmic/endoplasmic reticulum calcium ATPase2a (SERCA2a)/phospholamban complex, leading to leaky calcium channels. Leaky channels deplete calcium, which depolarizes cardiomyocytes, leading to arrhythmias, and conspires to down-regulate SERCA2a, which further depletes sarcoplasmic reticular calcium. than one.

\section{Reference} 2020;159:1809-19.e3.

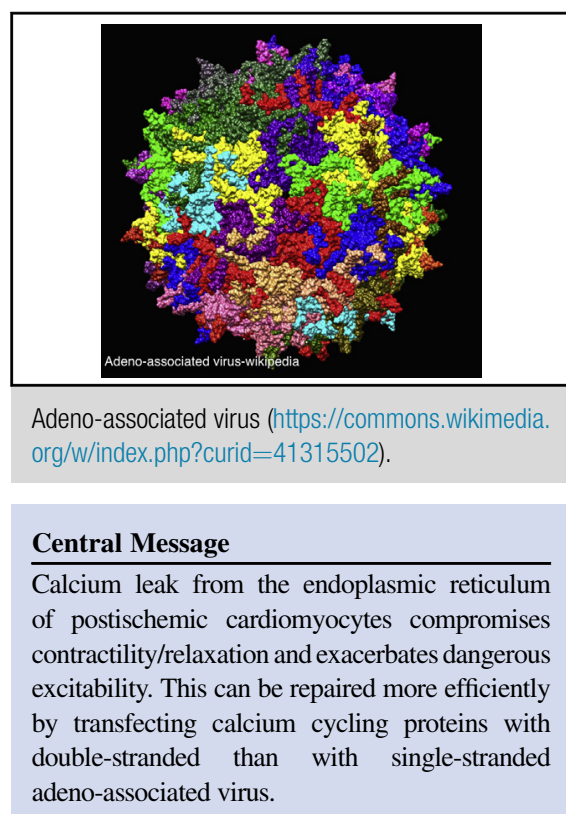

See Article page 1809.

Consequently, 2 therapeutic strategies are currently being tested in viral-mediated gene therapy clinical trials: fixing the leaky RyR2 channels with calcium release channel stabilizers (RyCals) and increasing expression of SERCA2a to enhance SR calcium reuptake. The authors report that transfection of the calcium sensor protein (S100A1) with both the single-stranded DNA genome and the selfcomplementary double-stranded DNA genome improved postinfarction remodeling - but two strands are better

We are not there yet, but Katz and colleagues attempt to communicate in language that is comprehensible by the target audience. We surgeons are as capable and likely to perform a Western blot as our basic science friends are of repairing an ascending aortic dissection. In the first instance, we would smear the blot, and in the second instance, the patient's family would likely be disappointed in the outcome. So, let's learn to talk to each other-two strands are always better than one.

1. Katz MG, Gubara SM, Hadas Y, Weder T, Kumar A, Eliyahu E, et al. Effects of genetic transfection on calcium cycling pathways mediated by double-stranded adeno-associated virus in postinfarction remodeling. J Thorac Cardiovasc Surg. 